\title{
Photoplethysmography using a smartphone application for assessment of ulnar artery patency: a randomized clinical trial
}

\author{
Pietro Di Santo MD, David T. Harnett MD, Trevor Simard MD, F. Daniel Ramirez MD, Ali Pourdjabbar MD, \\ Altayyeb Yousef MBBS, Robert Moreland MD, Jordan Bernick MSc, George Wells PhD, Alexander Dick MD, \\ Michel Le May MD, Marino Labinaz MD, Derek So MD, Pouya Motazedian BSc, Richard G. Jung BSc, \\ Jaya Chandrasekhar MD, Roxana Mehran MD, Aun-Yeong Chong MD, Benjamin Hibbert MD PhD
}

Cite as: CMAJ 2018 April 3;190:E380-8. doi: 10.1503/cmaj.170432

See related article at www.cmaj.ca/lookup/doi/10.1503/cmaj.180269

\section{ABSTRACT}

BACKGROUND: Radial artery access is commonly performed for coronary angiography and invasive hemodynamic monitoring. Despite limitations in diagnostic accuracy, the modified Allen test (manual occlusion of radial and ulnar arteries followed by release of the latter and assessment of palmar blush) is used routinely to evaluate the collateral circulation to the hand and, therefore, to determine patient eligibility for radial artery access. We sought to evaluate whether a smartphone application may provide a superior alternative to the modified Allen test.

METHODS: We compared the modified Allen test with a smartphone heart rate-monitoring application (photople- thysmography readings detected using a smartphone camera lens placed on the patient's index finger) in patients undergoing a planned cardiac catheterization. Test order was randomly assigned in a 1:1 fashion. All patients then underwent conventional plethysmography of the index finger, followed by Doppler ultrasonography of the radial and ulnar arteries (the diagnostic standard). The primary outcome was diagnostic accuracy of the heart ratemonitoring application.

RESULTS: Among 438 patients who were included in the study, we found that the heart rate-monitoring application had a superior diagnostic accuracy compared with the modified Allen test $(91.8 \% \mathrm{v}$. $81.7 \%, p=0.002)$, attributable to its greater specificity $(93.0 \%$ v. $82.8 \%, p=$ 0.001 ). We also found that this application had greater diagnostic accuracy for assessment of radial or ulnar artery patency in the ipsilateral and contralateral wrist $(94.0 \%$ v. $84.0 \%, p<0.001)$.

INTERPRETATION: A smartphone application used at the bedside was diagnostically superior to traditional physical examination for confirming ulnar patency before radial artery access. This study highlights the potential for smartphone-based diagnostics to aid in clinical decision-making at the patient's bedside. Trial registration: Clinicaltrials.gov, no. NCT02519491.
$\mathrm{T}$ he radial artery is used commonly for coronary angiography, percutaneous coronary intervention and invasive hemodynamic monitoring. Transradial access for coronary and peripheral interventions is used increasingly because of a lower incidence of vascular complications, patient preference and reduced mortality in patients with acute coronary syndrome..$^{1-4}$ Many of these benefits are attributed to superior postprocedural hemostasis given the superficial course and small calibre of the radial artery relative to the deeper and larger femoral vessel.
However, this small calibre also renders the radial artery prone to occlusion if proper anticoagulation and hemostatic practices are not followed ${ }^{5,6}$ - a complication that is reported to occur in up to one-third of patients. ${ }^{7}$ Despite dual blood supply to the hand via the ulnar and radial arteries, rare cases of substantial limb compromise have been reported after catheterization of the radial artery. ${ }^{8-10}$ Evaluating the competency of this dual blood supply before radial artery instrumentation continues to be performed routinely, ${ }^{11}$ despite questions raised about its value, ${ }^{12}$ and it 
remains endorsed by current interventional cardiac societies, ${ }^{13,14}$ as well as the World Health Organization. ${ }^{15}$

Colour Doppler ultrasonography imaging is the gold standard method for assessing arterial patency and collateral competency in this setting, ${ }^{16}$ but it is relatively resource-intensive and, therefore, seldom feasible or cost-effective in routine clinical practice. Assessment at the bedside using the modified Allen test is widely accepted as the clinical standard. Despite this test's known diagnostic and prognostic shortcomings ${ }^{16,17}$ and the low incidence of clinically significant ulnar artery occlusion, ${ }^{18}$ results from modified Allen tests have served to exclude as many as $27 \%$ of patients from transradial approaches for cardiac catheterization, and an abnormal modified Allen test remains a relative contraindication for placement of invasive hemodynamic monitoring. ${ }^{19}$ Plethysmography, which is the measurement of changes in amplitude of a photoelectric signal based on changes in blood volume pulsations, ${ }^{20}$ and pulse oximetry (commonly referred to as the Barbeau test) have been described as alternatives; however, the need for a dedicated oximeter has precluded its widespread use. Therefore, the modified Allen test remains the preferred method for assessment of dual circulation. ${ }^{11,21}$

Because of the widespread availability of smartphones, they are being used increasingly as point-of-care diagnostics in clinical settings with minimal or no cost. For example, built-in cameras with dedicated software or photodiode sensors using infrared light-emitting diodes have the potential to render smartphones into functional plethysmographs. However, robust evaluation of these technologies in clinical settings is lacking. We sought to evaluate the diagnostic accuracy of a smartphone-based heart rate-monitoring application compared with the modified Allen test for assessing dual circulation to the hand (ulnar artery patency) for transradial angiography.

\section{Methods}

\section{Study design and participants}

The CAPITAL iPhone-based evaluation of dual circulation before transRadial Access for Dlagnostic Angiography triaL (CAPITAL iRADIAL) was a prospective randomized clinical trial (RCT) conducted at the University of Ottawa Heart Institute between July 2015 and March 2016. We recruited patients from the hospital's coronary care unit, inpatient cardiology service and Regional Referral Centre/Day Unit if their clinical care plan included assessment for cardiac catheterization that included possible transradial access (Figure 1). Patients with a planned cardiac catheterization were eligible for inclusion. We excluded patients if hemodynamic instability was present, there was a need for emergent angiography (ongoing cardiac ischemia or ST-segment elevation myocardial infarction), the patient could not or would not provide informed consent or the patient had undergone previous surgical removal of the radial or ulnar artery. All participants provided written informed consent.

\section{Randomization and masking}

We randomly assigned participants $1: 1$ to either the modified Allen test or heart rate-monitoring application by using con- cealed envelopes prepared with a computer random sequence generator. Either the modified Allen test or heart rate-monitoring application were performed as the initial assessment based on group allocation. Subsequently, all participants underwent 3 additional assessments: either a modified Allen test or heart rate-monitoring application (whichever was not performed first), followed by plethysmography (Barbeau and reverse Barbeau) and Doppler ultrasonography of the radial and ulnar arteries. All assessments were conducted by the same co-investigator, and, therefore, blinding was not performed.

The modified Allen test was performed on all participants by having the patient make a fist for 30 seconds and with pressure applied over the radial and ulnar arteries to occlude them. The participant was then instructed to open the fist, and the ulnar artery was selectively released while the co-investigator monitored for return of colour to the hand (Figure 2, supplementary video 1 [Appendix 1, available at www.cmaj.ca/lookup/suppl/ doi:10.1503/cmaj.170432/-/DC1]). We coded the result as either ulnar artery patent (maximal palmar blush $\leq 5 \mathrm{~s}$ ) or occluded (maximal palmar blush occurring $>5 \mathrm{~s}$ ). This technique was then repeated by maintaining compression over the ulnar artery and releasing the compression over the radial artery ("reverse modified Allen test") and using the same coding criteria. A 5-second cut-off for arterial patency was chosen because it has been shown to maximize diagnostic accuracy (79.6\%), with a sensitivity of $75.8 \%$ and specificity of $81.7 \% .^{16}$

We conducted the smartphone-based evaluation by using the Instant Heart Rate application (version 4.5.0; Azumio) on an iPhone 4S (Apple). We selected this application because it permits direct visualization of the photoplethysmography tracing on the screen, is commercially available free of charge on both Apple and Android operating systems and is the most downloaded heart rate-monitoring application worldwide. The application software was initially developed for tracking heart rate in individuals without the need for dedicated equipment, using a proprietary algorithm by Azumio that was validated by comparing data collected via the application to electrocardiograms. The software utilizes the smartphone's camera light and lens to reflect light on an individual's finger, resulting in colour and brightness changes that are then extracted by the camera lens and interpreted as changes in pulse, reflected both as a numerical value (i.e., heart rate) and as a photoplethysmography tracing on the phone's screen.

We acquired photoplethysmography readings by placing the camera lens over the pulp of the participant's index finger with the hand resting on a firm surface and light pressure applied over the back of the camera (Figure 2, supplementary video 2 [Appendix 2, available at www.cmaj.ca/lookup/suppl/doi:10.1503/ cmaj.170432/-/DC2]). Readings were recorded before and immediately after isolated radial artery compression for 2 minutes or less and were divided into 4 categories as previously described by Barbeau and colleagues ${ }^{21}$ (i.e., A, no damping of pulse tracing immediately after radial artery compression; $B$, damping of pulse tracing; $C$, loss of pulse tracing followed by recovery of pulse tracing within 2 minutes; D, loss of pulse tracing without recovery within 2 minutes). Readings categorized as A or B indicated 


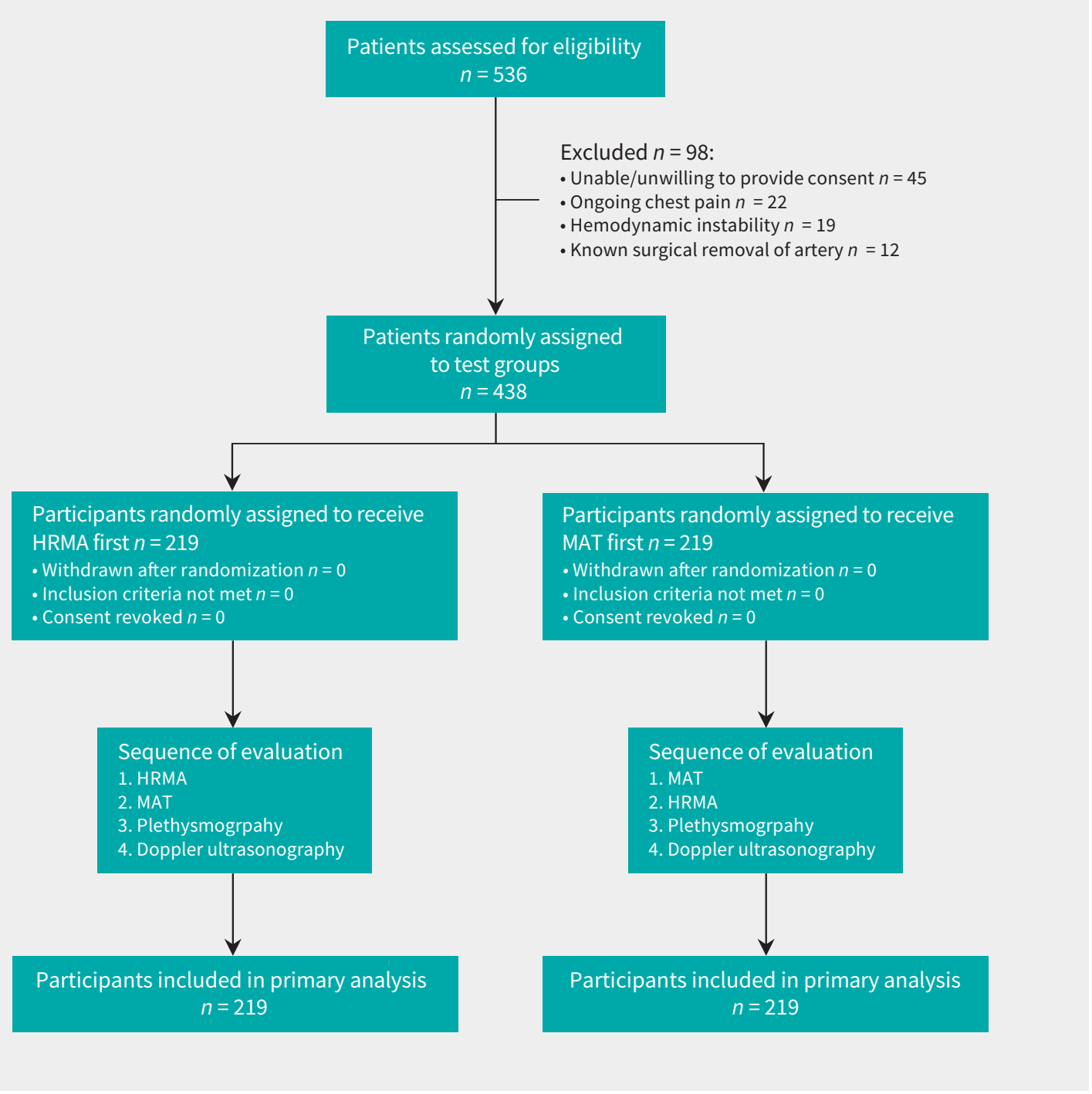

Figure 1: Participant recruitment and allocation. HRMA = heart rate-monitoring application, MAT = modified Allen test.

adequate flow, whereas those characterized as C or D indicated inadequate circulation.

We used a portable plethysmograph and pulse oximeter (Summit DME) for all participants after the assessments using the modified Allen test and heart rate-monitoring application, and before the assessments conducted with Doppler ultrasonography. We classified readings from plethysmography by using the same criteria as for the heart rate-monitoring application. We performed Doppler ultrasonography by using a linear transducer probe at both left and right wrists (Hitachi Noblus). We used both short and long axis views to visualize and measure radial and ulnar arteries. We measured maximum lumen diameter, intimal thickness and colour Doppler with pulse wave velocities at $1 \mathrm{~cm}$ proximal to the styloid process of the radius. ${ }^{22}$

\section{Outcomes}

Our primary outcome was overall diagnostic accuracy (the total number of true positives and true negatives as a proportion of the entire sample size) of the heart rate-monitoring application or modified Allen test for assessing collateral blood supply to the hand. For the primary analysis, we used only the first test to which the patient was randomly assigned to evaluate diagnostic accuracy, and then we compared test accuracy between the 2 randomly asssigned groups. We used the complete absence of any detectable Doppler flow of the ulnar artery as the reference standard for a positive modified Allen test or heart rate-monitoring application. We used the diagnostic accuracy of the heart ratemonitoring application for radial or ulnar artery patency from both right and left wrists (irrespective of expected primary access site) as a secondary outcome.

We evaluated prespecified variables to determine the predictors of poor diagnostic performance for the heart rate-monitoring application. We also compared the diagnostic accuracy of the application to that of conventional plethysmography. In addition, we conducted a post hoc analysis to determine if a stepwise approach to dual circulation assessment, specifically performing 


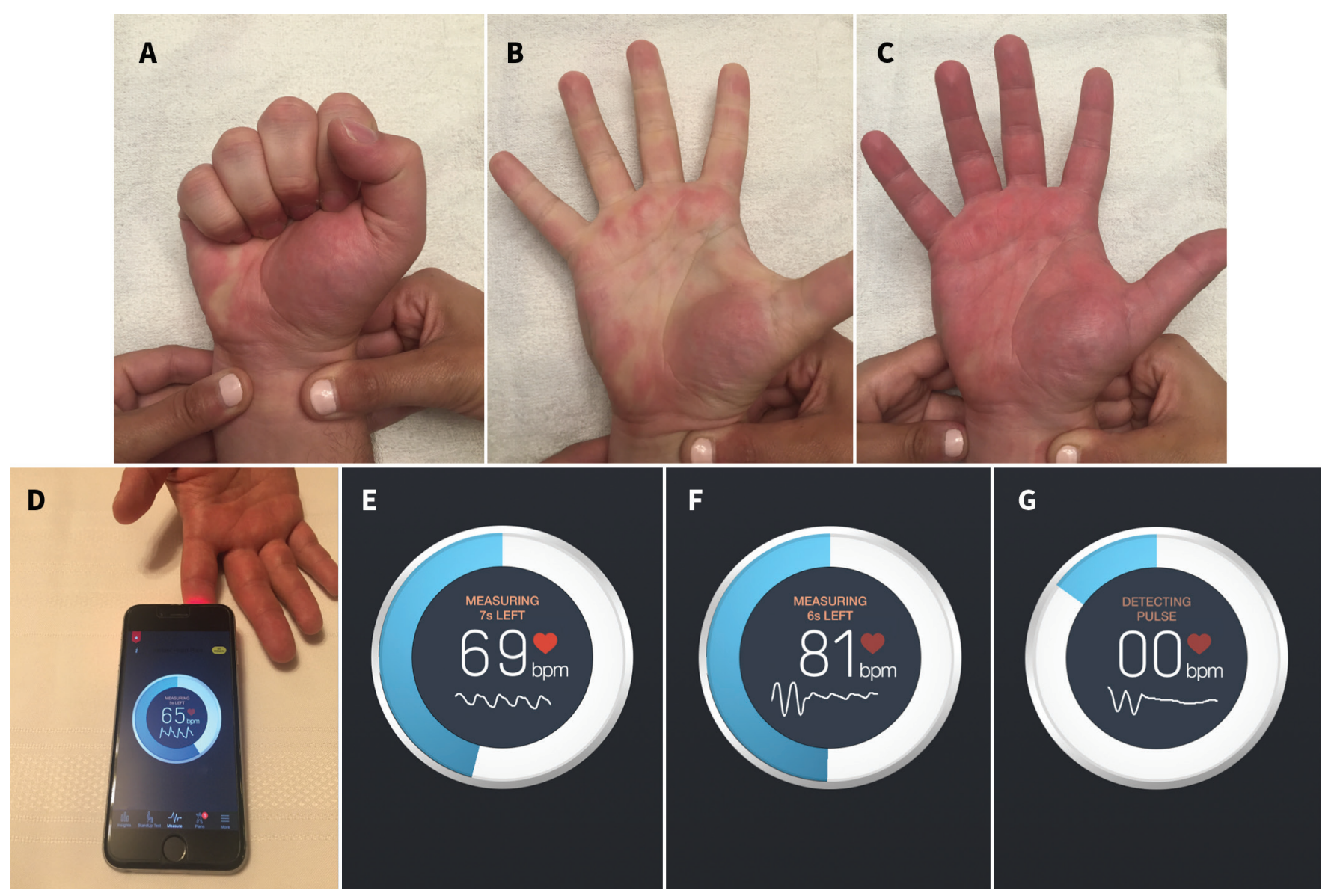

Figure 2: Demonstration of the modified Allen test and the smartphone-based heart rate-monitoring application. (A) Bilateral occlusion of the radial and ulnar arteries followed by clenching and opening of the hand 3 times. (B) Release of compression of the ulnar artery with blanching of the hand. (C) Restoration of palmar blush within 5 seconds, suggesting patency of the ulnar artery. (D) Placement of the smartphone camera on the index finger. (E) Screenshot capture of the instant heart rate interface showing a normal photoplethysmographic tracing below the participant's heart rate with isolated radial artery compression. (F) Dampening of the pulse tracing with isolated radial artery compression. (G) Loss of the pulse tracing with radial artery compression. Note: $\mathrm{bpm}=$ beats per minute.

the modified Allen test followed by the use of the heart ratemonitoring application in cases of positive modified Allen test results, resulted in greater diagnostic accuracy compared to the modified Allen test alone.

\section{Statistical analysis}

We assumed a diagnostic accuracy of $80 \%$ using the modified Allen test, ${ }^{16}$ and 438 participants were calculated to achieve $80 \%$ power to detect a $10 \%$ difference in diagnostic accuracy using the heart rate-monitoring application. All continuous variables are reported as means (standard deviation). Categorical variables are described as number (\%). Comparisons between diagnostic arms were performed using $\chi^{2}$ or Fisher exact tests. Within arm comparisons were performed using McNemar tests when comparing proportions for paired data. We analyzed artery-level data by using generalized estimating equations. We took clustering into account for those participants who had multiple arteries assessed. We used logistic regression to generate the model for predictors of false-positive assessment. All calculations were performed using SAS version 9.4 (SAS Institute). Our research protocol can be found in Appendix 3 (available at www.cmaj.ca/
lookup/suppl/doi:10.1503/cmaj.170432/-/DC3). The study was registered with clinicaltrials.gov (NCT02519491).

\section{Ethics approval}

The study was approved by the Ottawa Health Science Network Research Ethics Board.

\section{Results}

A total of 536 patients were screened, of whom 438 were included (Figure 1). Patient characteristics were comparable between the modified Allen test and heart rate monitoring application arms (Table 1). Nearly half of the participants in each group had previously undergone coronary angiography or had a documented history of arterial line insertion. Medical therapy, including nitrates and anticoagulants, was similar between the groups. The right radial artery was the potential primary access site in $75.8 \%$ of participants, and maximal vessel and lumen diameters were similar between the 2 groups. The median baseline lumen diameter was 2.1 (interquartile range 1.8-2.5) $\mathrm{mm}$, and comparable proportions of patients within each Barbeau class were randomly assigned to the arms. 


\section{Primary outcome: ulnar artery patency} assessment

Absence of ulnar flow by Doppler ultrasonography in the homolateral limb was found in 10 participants ( 6 in the heart rate-monitoring application group and 4 in the modified Allen test group). Diagnostic accuracy was $10.1 \%$ higher using the heart rate-monitoring application compared to that with the modified Allen test for determining ulnar artery patency $(91.8 \%, 95 \%$ confidence interval $[\mathrm{Cl}] 87.3 \%$ to $95.1 \%$ v. $81.7 \%, 95 \% \mathrm{Cl} 76.0 \%$ to $86.6 \%, p=0.002$, Table 2). This was caused by greater specificity with the heart rate-monitoring application $(93.0 \%$, $95 \% \mathrm{Cl} 88.7 \%$ to $96.0 \%$ v. $82.8 \%, 95 \% \mathrm{Cl} 77.1 \%$ to $87.6 \%, p=0.001)$. On a per-participant basis, 15 participants $(6.8 \%)$ in the heart rate-monitoring application group and $37(16.9 \%)$ in the modified Allen test group had false-positive results and would have been incorrectly excluded from radial artery access. Neither sensitivity $(50.0 \%, 95 \% \mathrm{Cl} 11.8 \%$ to $88.2 \%$ v. $25.0 \%, 95 \% \mathrm{Cl} 0.6$ to $80.6, p=0.6$ ) nor positive predictive value differed between the heart rate-monitoring application and the modified Allen test groups $(16.7 \%, 95 \% \mathrm{Cl} 3.6 \%$ to $41.4 \%$ v. $2.6 \%$, $95 \% \mathrm{Cl} 0.7 \%$ to $13.8 \%, p=0.09$ ). The negative predictive value was $98.3 \%$ ( $95 \% \mathrm{Cl} 95.2 \%$ to $99.7 \%$ ) for the modified Allen test group compared to $98.5 \%$ (95\% $\mathrm{Cl} 95.7 \%$ to $99.7 \%)$ in the heart rate-monitoring application group $(p=1.0)$.

\section{Dual circulation assessment in all arteries}

In total, 1472 arteries were assessed using the modified Allen test, heart rate-monitoring application, plethysmography and Doppler ultrasonography in both homolateral and contralateral limbs (Table 3). The discriminatory power of the heart rate-monitoring application remained greater than that of the modified Allen test, with a diagnostic accuracy of $94.0 \%(95 \% \mathrm{Cl} 91.9 \%$ to $95.6 \%)$ compared to $84.0 \%$ (95\% Cl $79.9 \%$ to $97.4 \%$ ), respectively $(p<0.001)$. We did not observe any differences in diagnostic performance of the modified Allen test or heart rate-monitoring application when we compared radial and ulnar assessments $(p>0.05)$.

\section{Predictors of false-positive assessments}

We included age, sex, body mass index (BMI) and presence of a palpable pulse as variables in the model. Thirty-seven participants in the modified Allen test cohort and 15 in the heart rate-monitoring application cohort had false-positive assessments. In the modified Allen test cohort, we found that age, male sex and BMI were not significant; however, the presence of a palpable ulnar artery significantly decreased the odds of having a false-positive result (odds ratio [OR] $0.06,95 \% \mathrm{Cl} 0.02$ to 0.25 ).

Sex, male

Ethnic origin

White

Nonwhite

Diabetes

Smoking

\section{Medications}

$\beta$-Blocker

Statin

Warfarin

Bivalirudin

Nitrate
Table 1: Participant characteristics

\section{Characteristic}

Age, yr; mean $\pm S D$

Height, $m$; mean \pm SD

Weight, kg; mean \pm SD

Body mass index, $\mathrm{kg} / \mathrm{m}^{2}$; mean $\pm \mathrm{SD}$

Heart rate, bpm; mean \pm SD

199 (90.9)

$20(9.1)$

$208(95.0)$

Medical history

Hypertension

$144(65.8)$

$149(68.0)$

90 (41.1)

78 (35.6)

Family history of premature coronary

artery disease*

Dyslipidemia

59 (26.9)

67 (30.6)

48 (21.9)

$50(22.8)$

Previous myocardial infarction

Previous angiography

$135(61.6)$

$151(68.9)$

101 (46.1)

$105(47.9)$

Previous percutaneous coronary intervention

$109(49.8)$

107 (48.9)

Previous coronary artery bypass graft

$76(34.7)$

72 (32.9)

Previous stroke

38 (17.4)

42 (19.2)

$13(5.9)$

Previous arterial line

$27(12.3)$

Angiotensin-converting enzyme inhibitor/

angiotensin receptor blocker

20 (9.1)

29 (13.2)

$112(51.1)$

Acetylsalicylic acid

Clopidogrel/ticagrelor

$108(49.3)$

$149(68.0)$

$169(77.2)$

$167(76.3)$

$161(73.5)$

$168(76.7)$

$162(74.0)$

91 (41.6)

Direct oral anticoagulant

$98(44.7)$

26 (11.9)

Unfractionated heparin

$18(8.2)$

$6(2.7)$

24 (11.0)

Low-molecular-weight heparin

$15(6.8)$

Note: $\mathrm{bpm}=$ beats per minute, $\mathrm{SD}=$ standard deviation.

${ }^{*}$ Defined as having a first-degree relative with clinically overt coronary artery disease (myocardial infarction, angina pectoris, need for coronary artery revascularization) before age 55 years (men) or 65 years (women). tUnless otherwise specified.
Similarly, for the heart rate-monitoring application cohort, the only significant variable in the model was the presence of a palpable pulse (OR $0.04,95 \% \mathrm{Cl} 0.01$ to 0.15 ). 
Table 2: Diagnostic accuracy of the modified Allen test and the heart rate-monitoring

application for assessing potential primary access sites

\begin{tabular}{|c|c|c|c|}
\hline Parameter & $\begin{array}{c}\text { No. }(\%) \text { of } \\
\text { participants, } ¥ \\
\text { modified Allen test } \\
n=219\end{array}$ & $\begin{array}{c}\text { No. }(\%) \text { of participants, } ¥ \\
\text { heart rate-monitoring } \\
\text { application } \\
n=219\end{array}$ & $p$ value§ \\
\hline Positive test result* & $38(17.4)$ & $18(8.2)$ & 0.008 \\
\hline Overall diagnostic accuracy, \% (95\% Cl) & 81.7 (76.0 to 86.6$)$ & 91.8 (87.3 to 95.1$)$ & 0.002 \\
\hline Specificity, \% (95\% Cl) & 82.8 (77.1 to 87.6$)$ & 93.0 (88.7 to 96.0$)$ & 0.001 \\
\hline Sensitivity, \% (95\% Cl) & 25.0 (0.6 to 80.6$)$ & 50.0 (11.8 to 88.2$)$ & 0.6 \\
\hline Negative predictive value, $\%(95 \% \mathrm{Cl})$ & 98.3 (95.2 to 99.7 ) & 98.5 (95.7 to 99.7 ) & 1.0 \\
\hline Positive predictive value, $\%(95 \% \mathrm{Cl})$ & $2.6(0.7 \mathrm{v} 13.8)$ & 16.7 (3.6 to 41.4$)$ & 0.09 \\
\hline Positive likelihood ratio $(95 \% \mathrm{Cl})$ & $1.5(-1.1$ to 4.0$)$ & 7.1 (0.4 to 13.8$)$ & \\
\hline Negative likelihood ratio $(95 \% \mathrm{Cl})$ & 0.9 (0.4 to 1.4$)$ & $0.5(0.1$ to 1.0$)$ & \\
\hline \multicolumn{4}{|l|}{ Barbeau classification $\dagger$} \\
\hline Class A & $123(56.2)$ & $111(50.7)$ & 0.3 \\
\hline Class B & $79(36.1)$ & $93(42.5)$ & 0.2 \\
\hline Class C & $16(7.3)$ & $13(5.9)$ & 0.5 \\
\hline Class D & $1(0.5)$ & $2(0.9)$ & 0.6 \\
\hline \multicolumn{4}{|c|}{$\begin{array}{l}\text { Note: } \mathrm{Cl}=\text { confidence interval. } \\
\text { ”A positive result indicates that there is inadequate collateral blood flow; this includes all true-positive and false-positive results. } \\
\text { †Barbeau classification was based on conventional plethysmography results: class } \mathrm{A} \text {, no damping of pulse tracing immediately after } \\
\text { radial artery compression; class B, damping of pulse tracing; class C, loss of pulse tracing followed by recovery of pulse tracing within } \\
2 \text { minutes; class D, loss of pulse tracing without recovery within } 2 \text { minutes. } \\
\text { fUnless specified otherwise. } \\
\text { SValues of } p \text { were generated using the Fisher exact test for between-arm comparisons. }\end{array}$} \\
\hline
\end{tabular}

\section{Stepwise evaluation of dual circulation}

We evaluated the clinical utility of sequential testing by determining the impact of the heart rate-monitoring application on participants who had a positive modified Allen test (i.e., palmar blush $>5 \mathrm{~s}$ ). Of the patients randomly assigned to the modified Allen test cohort for our primary analysis, $38(17.4 \%)$ participants had a positive modified Allen test and would be excluded from radial instrumentation. Of these participants, 36 had a subsequent normal heart rate-monitoring application assessment, thereby reclassifying these participants as having a patent ulnar artery. When compared with the use of the modified Allen test alone, this stepwise approach had a superior diagnostic accuracy (95.4\%, 95\% Cl 91.8\%-97.8\% v. $81.7 \%$, 95\% Cl 76.0\%-86.6\%, $p<0.001)$. This improved accuracy was caused predominantly by a superior specificity with the heart rate-monitoring application (96.7\%, $95 \%$ Cl $93.4 \%-96.7 \%$ v. $82.8 \%, 95 \%$ Cl $77.1 \%-87.6 \%$, $p<0.001)$.

\section{Comparison of the heart rate-monitoring application and conventional plethysmography}

To further evaluate its performance, we compared the overall diagnostic accuracy of the heart rate-monitoring application with that of conventional plethysmography. The application had a $94.0 \%$ accuracy compared to $93.5 \%$ with conventional plethysmography in all of the arteries that were assessed $(p=0.7)$. Although the heart rate-monitoring application showed superior accuracy relative to the modified Allen test, it was comparable to that of conventional plethysmography.

\section{Adverse events}

There were no procedural related complications during this study. Fourteen participants had an in-hospital major adverse cardiac event (i.e., myocardial infarction, stroke or death); 10 were in the modified Allen test cohort (5 patients with stroke, 1 with myocardial infarction and 4 deaths) and 4 were in the heart rate-monitoring application cohort ( 2 patients with myocardial infarctions and 2 deaths).

\section{Interpretation}

This proof of concept study implemented the photoplethysmographic capability widely available in smartphones for point-ofcare evaluation of arterial patency - in this instance, for the assessment of dual circulation before radial artery access for cardiac catheterization or hemodynamic monitoring. We have shown that use of a heart rate-monitoring application has the potential to improve diagnostic accuracy relative to the modified Allen test - the widely used clinical standard. In our study, the incidence of ulnar artery occlusion as assessed by Doppler ultrasonography was low, and the increased diagnostic discriminatory power of the heart rate-monitoring application was primarily caused by a reduction in false-positive tests. Thus, our study 
Table 3: Diagnostic accuracy of each test for ulnar and radial arteries

\begin{tabular}{|c|c|c|c|}
\hline Parameter & $\begin{array}{l}\text { Examined using the } \\
\text { modified Allen test }\end{array}$ & $\begin{array}{l}\text { Examined using the } \\
\text { heart rate-monitoring } \\
\text { application }\end{array}$ & $p$ valuet \\
\hline \multicolumn{4}{|l|}{ Ulnar artery assessment, $n=736$} \\
\hline No. (\%) of positive test results* & $126(17.1)$ & $49(6.7)$ & $<0.001$ \\
\hline Overall diagnostic accuracy, \% (95\% Cl) & $84.0(79.1$ to 87.9$)$ & 92.1 (88.7 to 94.6$)$ & 0.002 \\
\hline Specificity, \% (95\% Cl) & 84.6 (79.6 to 88.5$)$ & 93.3 (90.2 to 95.5$)$ & $<0.001$ \\
\hline Sensitivity, \% (95\% CI) & $40.0(14.3$ to 72.7$)$ & 37.5 (12.5 to 71.5$)$ & 0.9 \\
\hline Positive likelihood ratio $(95 \% \mathrm{Cl})$ & $2.6(-0.3$ to 5.4$)$ & $5.6(0.1$ to 11.1$)$ & \\
\hline Negative likelihood ratio $(95 \% \mathrm{Cl})$ & $0.7(0.2$ to 1.2$)$ & 0.7 (0.3 to 1.0$)$ & \\
\hline \multicolumn{4}{|l|}{ Radial artery assessment, $n=736$} \\
\hline No. (\%) of positive test results* & $102(13.9)$ & $30(4.1)$ & $<0.001$ \\
\hline Overall diagnostic accuracy, $\%(95 \% \mathrm{Cl})$ & 84.0 (76.6 to 87.6$)$ & 95.9 (93.4 to 97.5$)$ & $<0.001$ \\
\hline Specificity, \% (95\% Cl) & $85.6(81.1$ to 89.1$)$ & 96.9 (94.6 to 98.3$)$ & $<0.001$ \\
\hline Sensitivity, \% (95\% Cl) & 46.7 (25.4 to 69.2$)$ & $50.0(23.1$ to 76.9$)$ & 0.9 \\
\hline Positive likelihood ratio $(95 \% \mathrm{Cl})$ & $3.2(1.3$ to 5.2$)$ & $16.4(1.5$ to 31.2$)$ & \\
\hline Negative likelihood ratio $(95 \% \mathrm{Cl})$ & $0.6(0.3$ to 0.9$)$ & $0.5(0.2$ to 0.9$)$ & \\
\hline \multicolumn{4}{|l|}{ All arteries assessed, $n=1472$} \\
\hline No. (\%) of positive test results* & $228(15.5)$ & $79(5.4)$ & $<0.001$ \\
\hline Overall diagnostic accuracy, \% (95\% Cl) & 84.0 (79.9 to 87.4$)$ & 94.0 (91.9 to 95.6$)$ & $<0.001$ \\
\hline Specificity, \% (95\% Cl) & 85.1 (80.9 to 88.5$)$ & 95.1 (93.2 to 96.6$)$ & $<0.001$ \\
\hline Sensitivity, $\%(95 \% \mathrm{CI})$ & 45.0 (26.4 to 65.2$)$ & 43.8 (23.9 to 65.9$)$ & 0.9 \\
\hline Positive likelihood ratio $(95 \% \mathrm{Cl})$ & $3.0(1.5$ to 4.6$)$ & 9.0 (3.2 to 17.8$)$ & \\
\hline Negative likelihood ratio $(95 \% \mathrm{Cl})$ & 0.6 (0.4 to 0.9$)$ & 0.6 (0.3 to 0.8$)$ & \\
\hline
\end{tabular}

shows the utility of a smartphone for point-of-care diagnostics with numerous clinical applications.

Mobile digital technology has been ubiquitously and rapidly integrated into workplaces, yet the development, evaluation and validation of smartphones for point-of-care diagnostics has lagged. ${ }^{23}$ Barriers to the acceptance of mobile health technologies among health care providers include concerns regarding their efficacy and safety, ease of use, risk to patient confidentiality and diagnostic accuracy. ${ }^{24}$ For example, a recent study highlighted inaccuracies in assessments of blood pressure by an application sold to nearly 150000 users, by providing falsely reassuring blood pressure levels with hypertensive readings. ${ }^{25}$ Although such cases warrant concern, considerable effort and resources are being invested in integrating diagnostics into smartphones for a wide array of conditions (e.g., Apple's ResearchKit). ${ }^{26}$ The current report highlights that a smartphone application can outperform the current standard of care and provide incremental diagnostic yield in clinical practice. However, as with all new interventions and technologies, rigorous and systematic evaluation is needed before clinical integration.
Although not our primary goal, our study adds to the growing body of evidence that assessment of dual circulation by current standards is inadequate and may be irrelevant to the selection of patients for transradial access for cardiac catheterization. First, our findings show the low incidence of ulnar artery occlusion and the lack of sensitivity associated with abnormal results from the modified Allen test or heart rate-monitoring application. Thus, routine assessment will both inappropriately exclude a higher number of patients from the benefits of transradial access while simultaneously failing to identify a substantial proportion of those patients with inadequate ulnar reserve. Second, some studies have shown the presence of recruitable vascular reserve in the hand that can prevent clinically evident ischemia after mechanical manipulation of the radial artery. ${ }^{27,28}$ This concept is supported clearly by studies that show the safety of using the homolateral ulnar artery for access in patients with occluded or unavailable radial artery access. ${ }^{29,30}$ Finally, no substantial numbers of ischemic complications were reported in our study or in other RCTs that evaluated transradial access., ${ }^{2,12,31}$ Thus, although the practice of assessment of dual circulation is prevalent and rooted in the 
culture of medicine and guidelines, the practice remains without a reasonable foundation of evidence to support its use.

Performing the modified Allen test before radial artery access is recommended currently by numerous medical societies - including before transradial cardiac catheterization, ${ }^{13,14}$ acquisition of arterial blood gases ${ }^{15}$ and harvesting of the radial artery for coronary artery bypass grafting. ${ }^{32}$ In addition, the reverse modified Allen test is performed commonly to assess for radial artery occlusion after transradial artery catheterization. Although Doppler ultrasonography remains the gold standard, the modified Allen test remains the predominant form of ulnar patency assessment because this test can be performed at point of care. Based on our results, if the modified Allen test is to be used, replacing it with a photoplethysmography-based assessment using a smartphone application has the potential to increase the number of patients eligible for radial artery access by $10 \%$ over standard clinical care.

\section{Limitations}

Our study has some limitations. As a proof of concept study, we wanted to show the utility of a smartphone to improve diagnostic accuracy, but it was not designed to detect any difference in ischemic adverse events from transradial access. However, given the low prevalence of clinically meaningful outcomes in transradial studies, adequately powered studies would be prohibitively large. Instead, if dual circulation assessment is to be used, our data support the use of the heart rate-monitoring application to achieve a higher diagnostic accuracy and specificity, thereby allowing clinicians to offer transradial access to a greater number of patients. We also used the absence of documented Doppler flow in the ulnar as the gold standard for inadequate ulnar collateral supply. In addition to static testing, methods that employ dynamic assessment of Doppler signals during radial artery compression have been described;22 however, none of these techniques are associated with better prognostication of adequate collateral flow, and thus we elected to use the most extreme case (i.e., absence of flow) as our standard. Furthermore, all testing was performed by the same co-investigator, which predisposed our study to verification bias; however, randomly assigning participants to either the heart rate-monitoring application or the modified Allen test for the initial assessment and then comparing the result to our reference standard was important in mitigating this bias. Finally, all testing was performed using an iPhone 4s smartphone and a specific version of the heart rate-monitoring application. Given the differences in software and hardware specifications, these results are not necessarily generalizable to all smartphone platforms nor to different photoplethysmographic applications.

\section{Conclusion}

We found that using a smartphone heart rate-monitoring application to assess ulnar artery patency had superior diagnostic accuracy than the clinical standard (modified Allen test). Although this application is not certified at present for use in health care by any regulatory body, our study highlights the potential for smartphone-based diagnostics to aid in clinical decision-making at the patient's bedside.

\section{References}

1. Jin C, Li W, Qiao SB, et al. Costs and benefits associated with transradial versus transfemoral percutaneous coronary intervention in China. J Am Heart Assoc 2016;5:e002684.

2. Valgimigli M, Gagnor A, Calabró P, et al.; MATRIX Investigators. Radial versus femoral access in patients with acute coronary syndromes undergoing invasive management: a randomised multicentre trial. Lancet 2015;385:2465-76.

3. Andò G, Capodanno D. Radial access reduces mortality in patients with acute coronary syndromes: results from an updated trial sequential analysis of randomized trials. JACC Cardiovasc Interv 2016;9:660-70.

4. Ruzsa Z, Nemes B, Pintér L, et al. A randomised comparison of transradial and transfemoral approach for carotid artery stenting: RADCAR (RADial access for CARotid artery stenting) study. Eurolntervention 2014;10:381-91.

5. Staniloae CS, Mody KP, Sanghvi K, et al. Histopathologic changes of the radial artery wall secondary to transradial catheterization. Vasc Health Risk Manag 2009;5:527-32.

6. Yonetsu T, Kakuta T, Lee T, et al. Assessment of acute injuries and chronic intimal thickening of the radial artery after transradial coronary intervention by optical coherence tomography. Eur Heart J 2010;31:1608-15.

7. Uhlemann M, Mobius-Winkler S, Mende M, et al. The Leipzig prospective vascular ultrasound registry in radial artery catheterization: impact of sheath size on vascular complications. JACC Cardiovasc Interv 2012;5:36-43.

8. Rhyne D, Mann T. Hand ischemia resulting from a transradial intervention: successful management with radial artery angioplasty. Catheter Cardiovasc Interv 2010;76:383-6.

9. Ruzsa Z, Pinter L, Kolvenbach R. Anterograde recanalisation of the radial artery followed by transradial angioplasty. Cardiovasc Revasc Med 2010;11:266.e1-4.

10. de Bucourt M, Teichgraber U. Digital ischemia and consecutive amputation after emergency transradial cardiac catheter examination. Cardiovasc Intervent Radiol 2012;35:1242-4

11. Bertrand OF, Rao SV, Pancholy S, et al. Transradial approach for coronary angiography and interventions: results of the first international transradial practice survey. JACC Cardiovasc Interv 2010;3:1022-31.

12. Valgimigli M, Campo G, Penzo C, et al. Transradial coronary catheterization and intervention across the whole spectrum of Allen test results. J Am Coll Cardiol 2014;63:1833-41.

13. Hamon M, Pristipino C, Di Mario C, et al.; European Association of Percutaneous Cardiovascular Interventions; Working Group on Acute Cardiac Care of the European Society of Cardiology; Working Group on Thrombosis on the European Society of Cardiology. Consensus document on the radial approach in percutaneous cardiovascular interventions: position paper by the European Association of Percutaneous Cardiovascular Interventions and Working Groups on Acute Cardiac Care ${ }^{\star \star}$ and Thrombosis of the European Society of Cardiology. Eurolntervention 2013;8:1242-51.

14. Caputo RP, Tremmel JA, Rao S, et al. Transradial arterial access for coronary and peripheral procedures: executive summary by the Transradial Committee of the SCAI. Catheter Cardiovasc Interv 2011;78:823-39.

15. WHO guidelines on drawing blood: best practices in phlebotomy - Annex I: Modfied Allen test. Geneva: World Health Organization; 2010. Available: www.ncbi. nlm.nih.gov/books/NBK138652/ (accessed 2016 June 2).

16. Jarvis MA, Jarvis CL, Jones PRM, et al. Reliability of Allen's test in selection of patients for radial artery harvest. Ann Thorac Surg 2000;70:1362-5.

17. McGregor AD. The Allen test - an investigation of its accuracy by fluorescein angiography. J Hand Surg Br 1987;12:82-5.

18. Bertrand OF, Carey PC, Gilchrist IC. Allen or no Allen: that is the question! J Am Coll Cardiol 2014;63:1842-4.

19. Benit E, Vranckx P, Jaspers L, et al. Frequency of a positive modified Allen's test in 1,000 consecutive patients undergoing cardiac catheterization. Cathet Cardiovasc Diagn 1996;38:352-4.

20. Dorlas JC, Nijboer JA. Photo-electric plethysmography as a monitoring device in anaesthesia. Application and interpretation. $\mathrm{Br} J$ Anaesth 1985;57:524-30.

21. Barbeau GR, Arsenault F, Dugas L, et al. Evaluation of the ulnopalmar arterial arches with pulse oximetry and plethysmography: comparison with the Allen's test in 1010 patients. Am Heart J 2004;147:489-93.

22. Habib J, Baetz L, Satiani B. Assessment of collateral circulation to the hand prior to radial artery harvest. Vasc Med 2012;17:352-61. 
23. Topol EJ, Steinhubl SR, Torkamani A. Digital medical tools and sensors. JAMA 2015;313:353-4.

24. Gagnon MP, Ngangue P, Payne-Gagnon J, et al. m-Health adoption by healthcare professionals: a systematic review. J Am Med Inform Assoc 2016;23:212-20.

25. Plante TB, Urrea B, MacFarlane ZT, et al. Validation of the instant blood pressure smartphone app. JAMA Intern Med 2016;176:700-2

26. ResearchKit Studies. Baltimore: John Hopkins Medicine; 2016 Jan. 1 [updated]. Available: www.hopkinsmedicine.org/news/publications/insight/ features/researchkit-studies (accessed 2016 Nov. 23)

27. Kim SY, Lee JS, Kim WO, et al. Evaluation of radial and ulnar blood flow after radial artery cannulation with 20 - and 22-gauge cannulae using duplex Doppler ultrasound. Anaesthesia 2012;67:1138-45.

28. Ikizler M, Entok E, Ozdemir C, et al. Neurological status and tissue perfusion changes after radial artery harvesting for myocardial revascularization: importance of the Allen Test. Thorac Cardiovasc Surg 2007;55:99-103.

29. Kedev S, Zafirovska B, Dharma S, et al. Safety and feasibility of transulnar catheterization when ipsilateral radial access is not available. Catheter Cardiovasc Interv 2014;83:E51-60.
30. Kwan TW, Ratcliffe JA, Chaudhry M, et al. Transulnar catheterization in patients with ipsilateral radial artery occlusion. Catheter Cardiovasc Interv 2013;82:E849-55.

31. Mehta SR, Jolly SS, Cairns J, et al. Effects of radial versus femoral artery access in patients with acute coronary syndromes with or without ST-segment elevation. J Am Coll Cardiol 2012;60:2490-9.

32. Baikoussis NG, Papakonstantinou NA, Apostolakis E. Radial artery as graft for coronary artery bypass surgery: advantages and disadvantages for its usage focused on structural and biological characteristics. J Cardiol 2014;63:321-8.

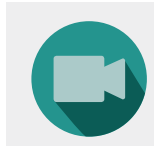

Please see the following videos online:

Demonstration of the procedure for the modified Allen test

Procedure for photoplethysmography readings obtained using a heart rate-monitoring application and a smartphone www.cmaj.ca/lookup/suppl/doi:10.1503/cmaj.170432/-/DC2
Competing interests: Roxana Mehran has received research grants paid to her institution from Astra Zeneca, The Medicines Company, Bristol-Myers Squibb/Sanofi, Eli Lilly and Company and Daiichi Sankyo outside the submitted work. She has received consultant fees from AstraZeneca, Bayer, CSL Behring, Janssen Pharmaceuticals, Merck \& Co., The Medicines Company and WaterMark Consulting. She has received renumeration as a member of the advisory boards of Abbott Laboratories, AstraZeneca, Boston Scientifc, Covidien, Janssen Pharmaceuticals, Merck \& Co., The Medicines Company and SanofiAventis. She holds less than 1\% equity in Claret Medical and Elixir Medical Corporation. No other competing interests were declared.

This article has been peer reviewed.

Affiliations: Division of Cardiology (Di Santo, Harnett, Simard, Ramirez Pourdjabbar,
Youssef, Dick, Le May, Labinaz, So, Chong, Hibbert); CAPITAL Research Group (Di Santo, Harnett, Simard, Ramirez, Youssef, Moreland, Dick, Le May, Labinaz, So, Motazedian, Jung, Chong, Hibbert); Vascular Biology and Experimental Medicine Laboratory (Simard, Jung, Hibbert); Cardiovascular Research Methods Centre (Bernick, Wells), University of Ottawa Heart Institute; Department of Cellular and Molecular Medicine (Simard, Hibbert); Department of Radiology (Moreland); School of Epidemiology, Public Health and Preventive Medicine (Ramirez, Wells), University of Ottawa, Ottawa, Ont:; Division of Cardiovascular Medicine (Pourdjabbar), Sulpizio Cardiovascular Center, University of California, San Diego, CA; Icahn School of Medicine at Mount Sinai (Chandrasekhar, Mehran), New York, NY

Contributors: All of the authors contributed substantially to the conception or design of the work, drafted the work and revised it crit- ically for important intellectual content, gave final approval of the version to be published and agreed to be accountable for all aspects of the work in ensuring that questions related to the accuracy or integrity of any part of the work are appropriately investigated and resolved.

Data sharing: The data used for this analysis are available upon request to Benjamin Hibbert with details of the proposed analysis. $A$ request will be reviewed and authorized once it is deemed scientifically justified.

Disclaimer: George Wells is a biostatistical consultant for CMAJ and was not involved in the editorial decision-making process for this article.

Accepted: Dec. 6, 2017

Correspondence to: Benjamin Hibbert, bhibbert@ottawaheart.ca 